\title{
Correction to: Relation of anatomy with function following the surgical treatment of idiopathic epiretinal membrane: a multicenter retrospective study
}

\author{
Sengul Ozdek ${ }^{1} \cdot$ Ece Ozdemir Zeydanli ${ }^{1,2} \cdot$ Levent Karabas $^{3} \cdot$ Mehmet Yasin Teke $^{4} \cdot$ Gursel Yilmaz $^{5} \cdot$ Mehmet Citirik $^{4}$. \\ Nilufer Kocak ${ }^{6} \cdot$ Hakan Durukan ${ }^{7}$. for the Turkish ERM Study Group
}

Published online: 24 February 2021

(C) Springer-Verlag GmbH Germany, part of Springer Nature 2021

\section{Correction to: Graefe's Archive for Clinical and Experimental Ophthalmology https://doi.org/10.1007/s00417-020-05002-1}

The published online version contains error.

In the article titled "Relation of anatomy with function following the surgical treatment of idiopathic epiretinal membrane: a multicenter retrospective study" one of the contributors' name and affiliation, 'Hulya Yazıcı, MD: Dr. Nafiz Korez Sincan State Hospital, Eye Clinic, Ankara, Turkey' has been inadvertently left out of the TERM Study Group list in the Appendix section.

The corrected list of Turkish ERM (TERM) Study Group as follows:

The online version of the original article can be found at https://doi.org/ 10.1007/s00417-020-05002-1

Sengul Ozdek

sengulozdek@gmail.com

1 Department of Ophthalmology, School of Medicine, Gazi University, 06500 Ankara, Turkey

2 Department of Ophthalmology, Ardahan State Hospital, 75000 Ardahan, Turkey

3 Department of Ophthalmology, School of Medicine, Kocaeli University, Kocaeli, Turkey

4 Ulucanlar Eye Training and Research Hospital, Ankara, Turkey

5 Department of Ophthalmology, School of Medicine, Başkent University, Ankara, Turkey

6 Department of Ophthalmology, School of Medicine, Dokuz Eylul University, Izmir, Turkey

7 Department of Ophthalmology, Gulhane Education and Research Hospital, Ankara, Turkey
Mehmet Numan Alp, MD; Remzi Avci, MD; Mehmet Citirik, MD; Sibel Demirel, MD; Hakan Durukan, MD; Cuneyt Erdurman, MD; Nur Acar Gocgil, MD; Hulya Gungel, MD; Dilek Guven, MD; Defne Kalayci, MD; Ziya Kapran, MD; Levent Karabas, MD; Murat Karacorlu, MD; Ozcan R. Kayıkcioglu, MD; Suleyman Kaynak, MD; Nilufer Kocak, MD; Rengin Aslihan Kurt, MD; Ozay Oz, MD; Sengul Ozdek MD, FEBO; Hakan Ozdemir, MD; Berna Ozkan, MD; Abdullah Ozkaya, MD; Ozlem Sahin, MD; Figen Sermet, MD; Sinan Tatlipinar, MD; Mehmet Yasin Teke, MD; Melih Unal, MD; Hulya Yazici, MD; Gursel Yilmaz, MD; Sami Yilmaz, MD

We deeply regret this error. 